\title{
Comparative analysis of in vitro accelerated glistening formation in foldable hydrophobic intraocular lenses
}

\author{
Tamer Tandogan • Gerd U. Auffarth (D) Chul Young Choi • Hyeck-Soo Son • \\ Ramin Khoramnia
}

Received: 20 December 2020/ Accepted: 15 April 2021/Published online: 19 May 2021

(C) The Author(s) 2021

\begin{abstract}
Purpose To analyse and compare the propensity to form glistenings in 4 different types of hydrophobic acrylic intraocular lenses (IOLs): Alcon AcrySof ${ }^{\circledR}$ MA60AC, HOYA iSert ${ }^{\circledR}$ PC-60AD, Bausch\&Lomb enVista, and Kowa Avansee ${ }^{\mathrm{TM}}$ PU6A.

Methods We used an accelerated laboratory method to create glistenings. IOLs were first immersed in saline at $45{ }^{\circ} \mathrm{C}$ for $24 \mathrm{~h}$ and then at $37{ }^{\circ} \mathrm{C}$ for $2.5 \mathrm{~h}$. Microvacuole (MV) density and size were
\end{abstract}

T. Tandogan · G. U. Auffarth ( $\square)$.

H.-S. Son · R. Khoramnia

The David J. Apple International Laboratory for Ocular Pathology and International Vision Correction Research Centre (IVCRC), Department of Ophthalmology, University of Heidelberg, INF 400, 69120 Heidelberg, Germany

e-mail: Gerd.Auffarth@med.uni-heidelberg.de

URL: http://www.ivcrc.com; http://www.djapplelab.com

T. Tandogan

e-mail: tandogan@mac.com

H.-S. Son

e-mail: hyecksoo.son@med.uni-heidelberg.de

R. Khoramnia

e-mail: ramin.khoramnia@med.uni-heidelberg.de

C. Y. Choi

Department of Ophthalmology, Kangbuk Samsung

Hospital, Sungkyunkwan University School of Medicine,

Seoul, Korea

e-mail: chulyoung.choi@gmail.com documented and calculated using an image analysis program.

Results Median density of glistenings $\left[\mathrm{MV} / \mathrm{mm}^{2}\right]$ for Alcon AcrySof ${ }^{\circledR}$ MA60AC was 623 (range 507-804), for HOYA iSert ${ }^{\circledR}$ PC-60AD 1358 (range 684-2699), for Bausch\&Lomb enVista 2 (range 1-2), and for Kowa Avansee ${ }^{\mathrm{TM}}$ PU6A 1 (range 1-4). The prevailing MV size was: $0-5 \mu \mathrm{m}$ for Hoya IOLs, 5-10 $\mu \mathrm{m}$ for Alcon IOLs, $20-50 \mu \mathrm{m}$ for Bausch\&Lomb IOLs, and 5-50 $\mu \mathrm{m}$ for Kowa IOLs.

Conclusions Glistenings could be induced in all studied IOLs using the accelerated laboratory method. The Alcon AcrySof ${ }^{\circledR}$ MA60AC and HOYA iSert ${ }^{\circledR}$ PC-60AD IOLs showed MV of high density, while the glistenings in the Hoya IOLs were smaller in size compared to the Alcon IOLs. The MV density was minimal in the Bausch\&Lomb enVista and Kowa Avansee $^{\mathrm{TM}}$ PU6A IOLs. The propensity of the Alcon AcrySof ${ }^{\circledR}$ MA60AC IOLs to form glistenings in vitro correlated with the findings of clinical results that are already published.

Keywords Intraocular lens - Laboratory analysis . Glistenings

\section{Introduction}

Glistenings describe small, refractive microvacuoles that arise within the biomaterial of intraocular lenses 
(IOLs) [1-4]. Studies have reported on their clinical significance as they may deteriorate the patients' visual acuity and contrast sensitivity [5-10].

Since 1984, such glistening formation has been described in different IOL materials such as rigid hydrophobic polymethyl methacrylate, foldable silicone, and foldable hydrophobic acrylate. According to an ASCRS survey, the foldable hydrophobic acrylic IOLs were currently the most commonly implanted IOLs [11]. The incidence of glistening formation and its severity are reported to be the highest with foldable hydrophobic acrylic materials [7, 12, 13].

The simulation of glistening formation in a laboratory setting can be achieved via an accelerated ageing process. Such in vitro studies are considered to give valuable information about the tendency of a given material to form glistenings [12, 14-20].

Several hydrophobic IOL materials have already been analysed under laboratory conditions to compare their tendency to create glistenings [14-20]. The Bausch\&Lomb enVista IOL is reported to be free of glistenings even 2 years after implantation, giving this IOL the label as being "glistening-free" [21]. Another new generation hydrophobic foldable IOL (Kowa Avanse ${ }^{\mathrm{TM}}$ ) has been introduced which purportedly does not have a propensity to develop any glistenings.

In this study, we compared the glistening formation of this IOL of Kowa (Kowa Avansee ${ }^{\mathrm{TM}}$ PU6A) to the FDA-approved glistening-free Bausch\&Lomb enVista IOL as well as to two widely used hydrophobic IOL materials, namely the materials in the hydrophobic HOYA iSert ${ }^{\circledR}$ PC-60AD IOL and the Alcon AcrySof ${ }^{R}$ MA60AC IOL, which have been extensively studied for their glistening formation previously [14-20, 22].

\section{Material and methods}

Five IOLs of each type were included in this comparative laboratory study: Alcon AcrySof ${ }^{\circledR}$ MA60AC, HOYA iSert ${ }^{\circledR}$ PC-60AD, Kowa Avansee ${ }^{\text {TM }}$ PU6KA and Bausch\&Lomb enVista. All IOLs had a dioptric power of $+20.0 \mathrm{D}$ and were composed of clear (not yellow tinted) hydrophobic acrylic material with an integrated UV inhibitor. Table 1 shows the material composition of the IOLs examined. All lenses analysed in the current study were newly manufactured at the time and suitable for implantation.
Using the now widely established methodology described by Thomes and Callaghan [14], glistenings were generated as aqueous-filled microvacuoles (MV) by using an accelerated laboratory ageing method in all IOLs. The IOLs were placed in bottles filled with saline solution. These bottles were placed in an oven set at $45{ }^{\circ} \mathrm{C} \pm 1{ }^{\circ} \mathrm{C}$. After $24 \mathrm{~h}$, the lenses were moved to a $37{ }^{\circ} \mathrm{C} \pm 1{ }^{\circ} \mathrm{C}$ water bath where they remained for another $2.5 \mathrm{~h}$. Afterwards, the samples were analysed. The equipment for IOL analysis consisted of a microscope (MEIJI EMZ-TR8) with a heated stage, a CCD camera, a computer, and an image analysing software (i-Solution). The IOLs were observed visually under the light microscope and analysed regarding size and density of the MV at a specified temperature. The heated stage allows maintenance of the temperature of the lens at $37{ }^{\circ} \mathrm{C}$ during imaging which helps to maintain MV size and density during imaging.

The entire lens was scanned and the region of maximum density (central or paracentral and at the right focal plane) was captured for analysis. The resultant images were examined using an image analysis program (Fig. 1). The data acquired from these images were used to measure the density and size of the MV (units: number of microvacuoles per square millimetre $\left[\mathrm{MVs} / \mathrm{mm}^{2}\right]$ ). Induced MVs were then classified depending on their size (Class 1: 0-5 $\mu \mathrm{m}$, Class 2: 5-10 $\mu \mathrm{m}$, Class 3: $10-15 \mu \mathrm{m}$, Class 4: 15-20 $\mu \mathrm{m}$, Class 5: 20-50 $\mu \mathrm{m}$, Class 6: 50-100 $\mu \mathrm{m}$, No Class: $>100 \mu \mathrm{m}$ ) and density [15].

\section{Results}

Glistenings were detectable in all lenses after the accelerated microvacuole test method (Fig. 2). However, differences were found between the different types of IOLs (Fig. 3). The HOYA iSert ${ }^{\circledR}$ PC-60AD and Alcon AcrySof ${ }^{\circledR}$ MA60AC IOLs showed rather high number of glistenings, while the Bausch\&Lomb enVista and Kowa Avansee ${ }^{\mathrm{TM}}$ PU6KA materials were almost completely free of glistenings (Table 2).

The difference in the MV density was statistically significant and the density was higher in HOYA iSert ${ }^{\circledR}$ PC-60AD lenses compared to Alcon AcrySof (B) MA60AC lenses. Both lenses showed higher MV density than the Bausch\&Lomb enVista and Kowa Avansee $^{\mathrm{TM}}$ PU6KA IOLs. There was no statistically 
Table 1 Material composition of the studied intraocular lenses

\begin{tabular}{ll}
\hline & Material composition \\
\hline $\begin{array}{l}\text { Alcon AcrySof } \\
\text { MA60AC }\end{array}$ & Copolymer of phenylethyl acrylate and phenylethyl methacrylate, cross-linked with butanediol diacrylate \\
$\begin{array}{l}\text { Hoya iSert }{ }^{\circledR} \text { PC-60AD } \\
\text { Bausch\&Lomb enVista }\end{array}$ & $\begin{array}{l}\text { Cross-linked copolymer of phenylethyl methacrylate and n-butyl acrylate, fluoroalkyl methacrylate } \\
\text { Hydrated to equilibrium water content and packaged in a physiological saline solution to prevent } \\
\text { glistening formation } \\
\text { Designed with a high water content to enhance exibility and foldability } \\
\text { Kowa Avansee } \\
\text { AU6KA }\end{array}$ \\
$\begin{array}{l}\text { Hydrophobic soft acrylic (UV-absorbing acrylic resin; natural type also contains proprietary blue light } \\
\text { filtering) }\end{array}$ \\
\hline
\end{tabular}

significant difference in the MV density between the Bausch\&Lomb enVista and Kowa Avansee ${ }^{\mathrm{TM}}$ PU6KA IOLs $(p<0.05$, Mann-Whitney $U$ test $)$ (Table 3).

In HOYA iSert ${ }^{\circledR}$ PC-60AD IOLs, the prevailing MV size was Class 1. The Alcon AcrySof ${ }^{\circledR}$ MA60AC IOLs and the Bausch\&Lomb enVista IOLs showed prevailing MV sizes of Class 2 and 5, respectively. The Kowa Avansee ${ }^{\mathrm{TM}}$ PU6KA IOLs showed a balanced distribution of MV size between Classes 2 and 5 (Table 4).

The MVs were predominantly located in the midperipheral region of the optic in the Bausch\&Lomb and Kowa IOLs. In contrast, the MVs were more densely distributed in the centre in Hoya and Alcon IOLs.

\section{Discussion}

The glistening phenomenon is clinically important because of its possible effect on vision. Some studies suggested that severe glistenings could mildly decrease contrast sensitivity and visual acuity $[8,11,23,24]$.

Glistenings describe fluid-filled microvacuoles that form within the matrix of the IOL material when it is exposed to an aqueous environment [14]. Since there is a significant difference in the refractive index of water droplets $(n=1.33)$ and the bulk polymer $(n=1.55)$, the light is refracted and scattered at the water-polymer interfaces which are then visible as "glistenings" [16]. Among others, they have been mostly reported in hydrophobic acrylic IOLs $[7,12,13]$.
We performed an IOL optical purity assessment by using temperature changes to accelerate the development of glistenings and quantified the density of the glistenings in different hydrophobic acrylic IOLs. Our results have shown that the Bausch\&Lomb IOLs, which are claimed to be glistening-free, as well as the Kowa IOLs showed only a negligible number of glistenings. In terms of MV size and density, the two IOLs did not show any statistically significant differences. Previously, two clinical studies reported that no glistenings were observed at any postoperative visit in the Bausch\&Lomb IOLs $[25,26]$. In our experiment, no IOL model was completely free of glistenings. However, the numbers were veryclose to zero in the Bausch\&Lomb and Kowa material.

Our results have also shown that the Alcon and the Hoya IOLs had a higher MV density than the Bausch\&Lomb and the Kowa IOLs. The Hoya IOL showed the smallest MV size compared to the other studied IOLs.

Regarding the localization of the MVs within the IOL optic, the Alcon and the Hoya IOLs showed a higher MV density at the central part of the optic, while the Kowa and the Bausch\&Lomb IOLs developed glistenings more at the mid-peripheral area of the optic, which may reduce the risk of a clinical impact in-vivo.

According to the glistening scoring scale described by Miyata et al. [15], the Kowa and the Bausch\&Lomb IOLs were classified as Grade 0, while the Hoya and Alcon IOLs were classified as Grade 3. These results correlated with those of a study by Kawai et al. in which the Alcon and Hoya IOLs showed glistenings after an accelerated glistening method, while the Kowa Avansee ${ }^{\mathrm{TM}}$ and the hydrophilic acrylic 
Fig. 1 Detection of glistenings from the native picture (90-fold magnification, left) using the imaging software $(i$ Solution) (right)
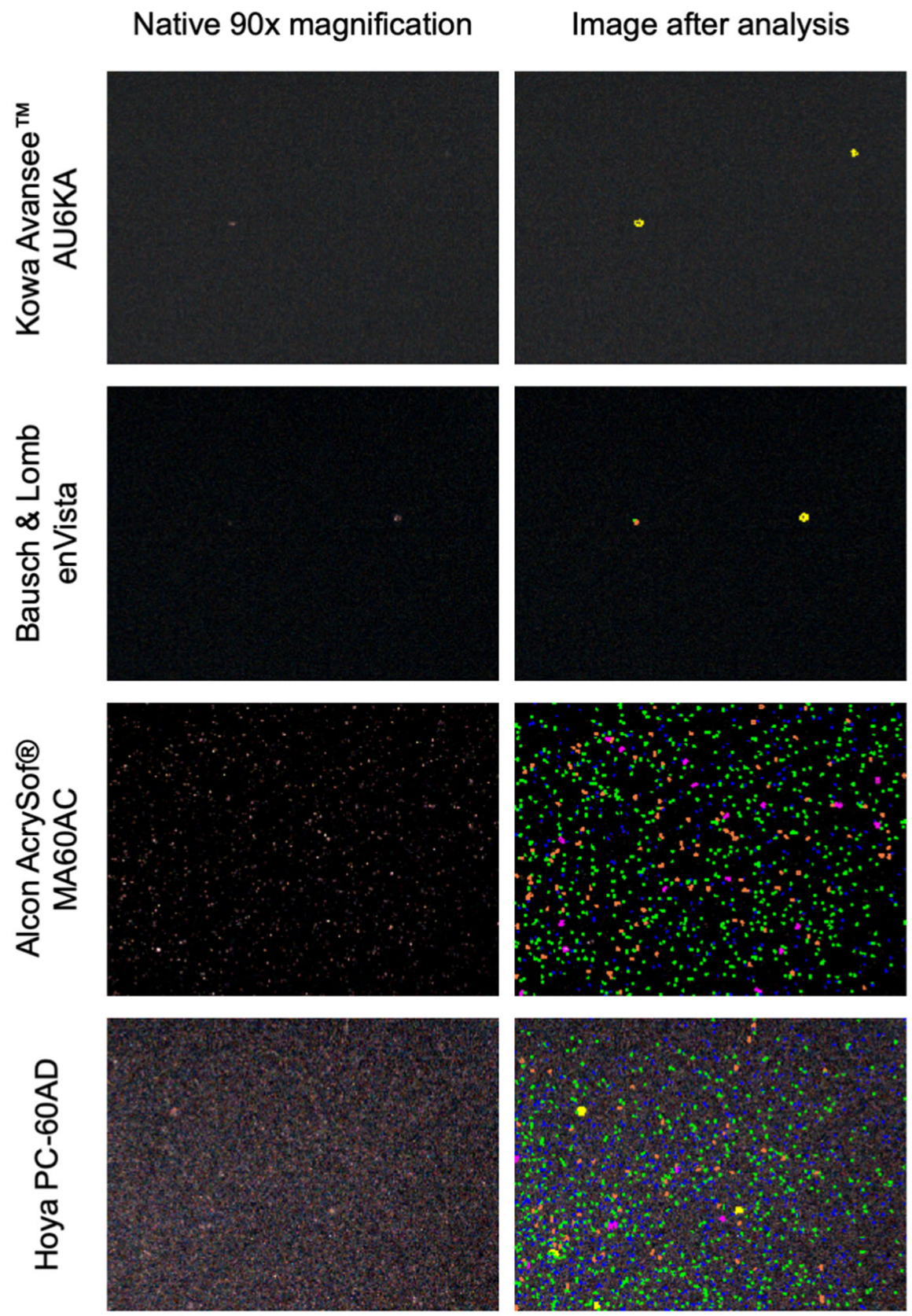

Bausch\&Lomb Hydroview IOLs did not [18]. However, the authors graded the glistenings distribution based only on a qualitative assessment in contrast to our qualitative, quantitative, and morphological assessment.

The tendency of the AcrySof material to form glistenings under laboratory conditions correlate well with the findings of clinical results which have already been published $[8,9]$. While there do exist differences in the number of glistenings observed for each IOL in different in vitro studies, it is important to note that there are generally variations of glistening development and size even within the same IOL model. While the HOYA IOLs also showed a strong tendency to generate glistenings that were smaller in size compared to those of the Alcon IOL and more diffusely distributed, there are no clinical data published to date regarding glistenings observed in-vivo with HOYA iSert ${ }^{\circledR}$ PC-60AD IOLs. 


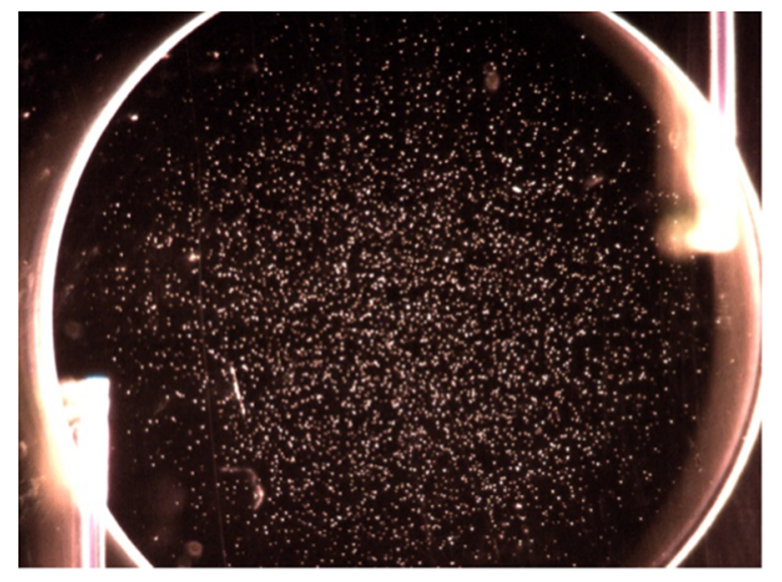

Alcon AcrySof $\Omega$

MA60AC

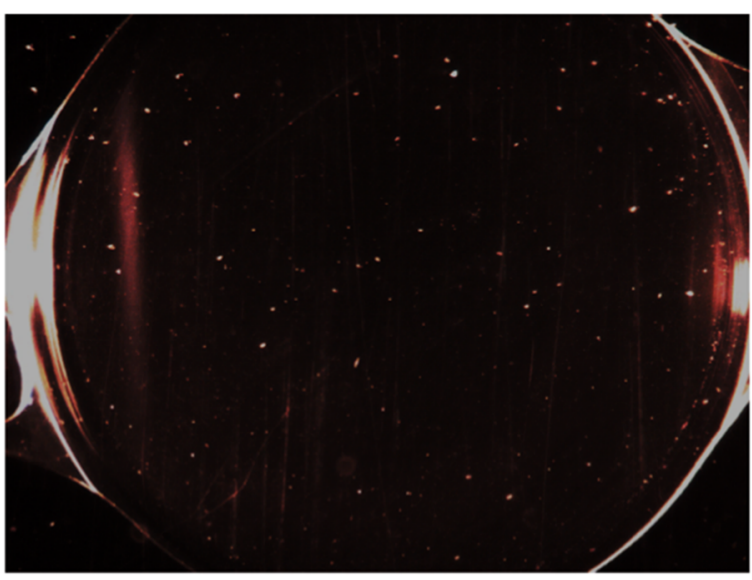

Bausch \& Lomb enVista

Fig. 2 Example of all 4 IOLs (14-fold magnification)

This may, in part, be due to the fact that the present study did not simulate the temperature fluctuations in the human eye. Although glistening formation induced in vitro by alteration of the temperature can produce morphological aspects that in general appear exaggerated in comparison to the clinical situation, in vitro studies are considered suitable for laboratory investigation [12, 18, 27]. It is uncertain whether glistenings produced with laboratory methods arise due to the same mechanism or are of the same kind as glistenings observed in patients [14]. The rate of the temperature fluctuations seems to have a significant impact on the extent of glistening formation. Although in vitro analysis may provide an assessment of the tendency of

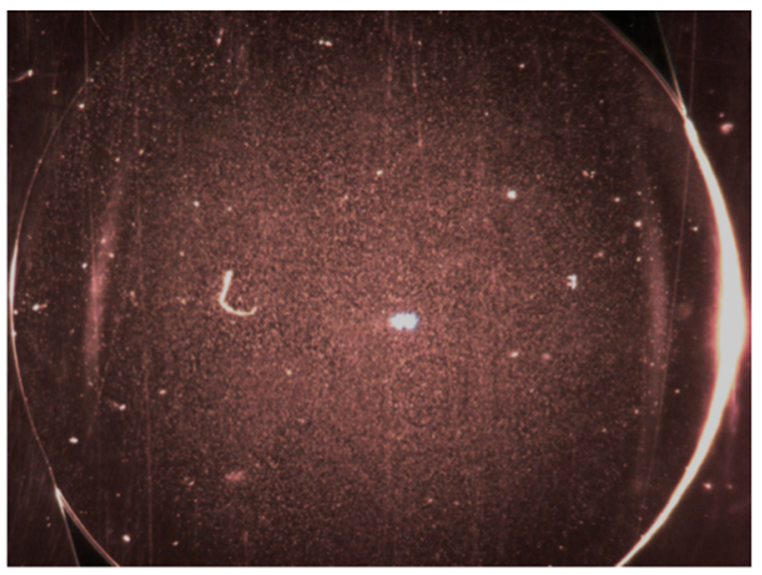

Hoya PC-60AD

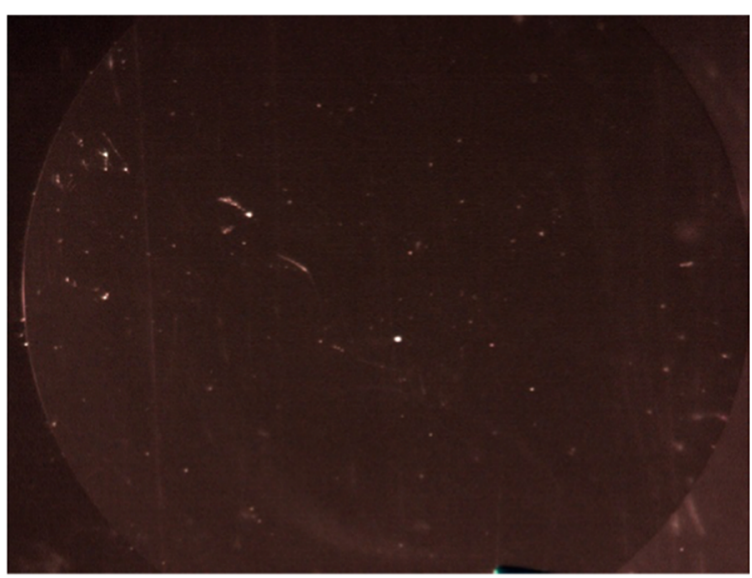

\section{Kowa Avansee ${ }^{\mathrm{TM}}$ AU6KA}

a material to form glistenings, the correlation between in vitro test results and in-vivo observations remains unclear. While some studies showed that there is no impact of glistenings on the visual quality [12, 28, 29], others reported deterioration of visual acuity, contrast sensitivity, and an increase in straylight $[5,6,23,30,31]$. Furthermore, the osmolarity of the fluid around the IOL may play a role as do comorbidities of the patients such as diabetes mellitus. Inflammations or an interrupted blood-aqueous barrier may also influence the outcome in every patient [1-3].

It has to be emphasized that the problem of glistenings seems to have been fully resolved by the 


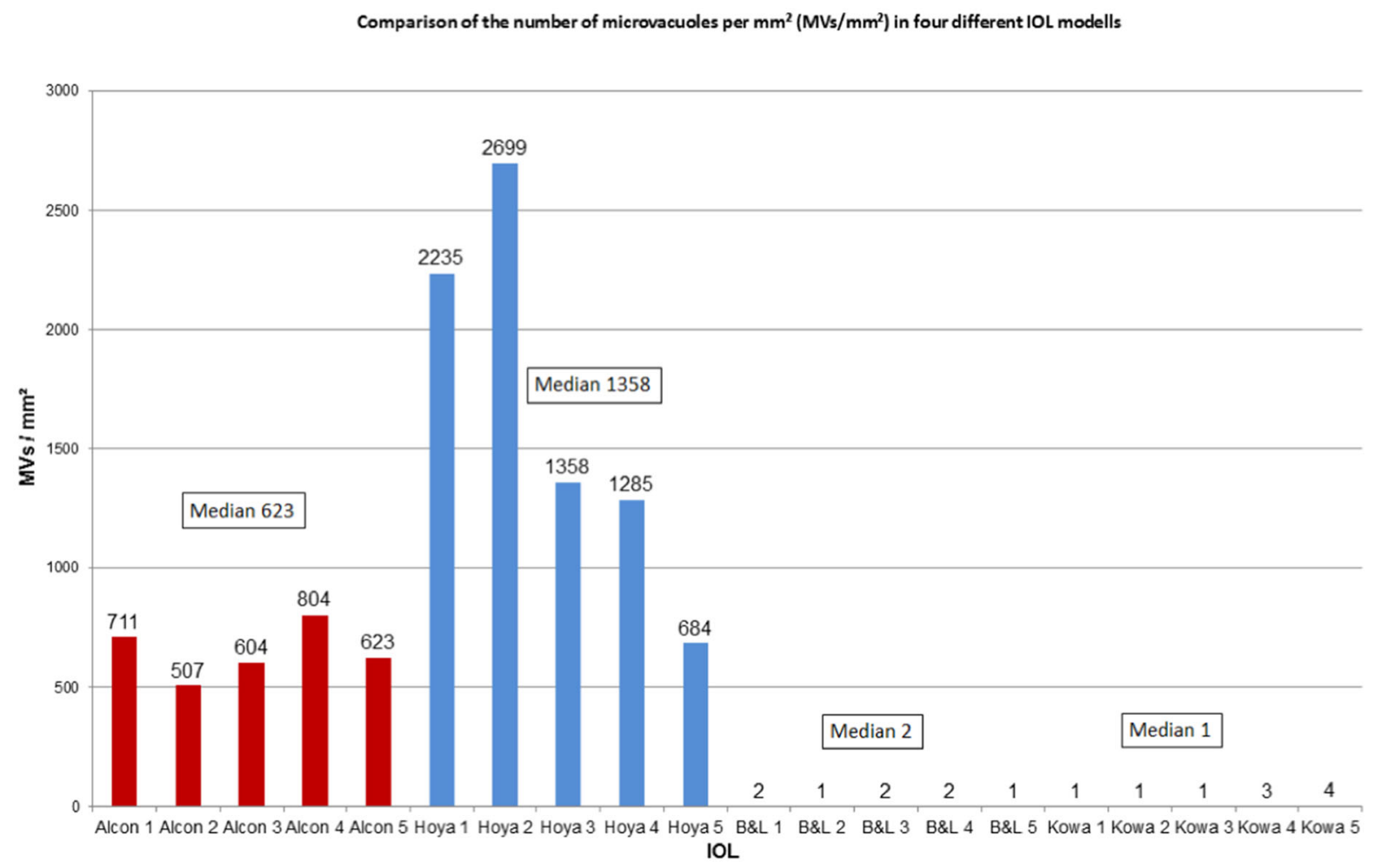

Fig. 3 Microvacuoles per $\mathrm{mm}^{2}$ : Data of all IOLs

Table 2 Scoring of the microvacuole density according to Miyata et al. [15]

\begin{tabular}{lll}
\hline & Microvacuoles $/ \mathrm{mm}^{2}$ & Grade according to Miyata et al. (Scale from 0 to 3) \\
\hline Alcon AcrySof ${ }^{\circledR}$ MA60AC & $>200$ & 3 \\
Hoya iSert ${ }^{\circledR}$ PC-60AD & $>200$ & 3 \\
Bausch\&Lomb enVista & $<5$ & 0 \\
Kowa Avansee ${ }^{\mathrm{TM}}$ AU6KA & $<5$ & 0 \\
\hline
\end{tabular}

Table 3 Statistical analysis of the microvacuole density

\begin{tabular}{|c|c|c|c|c|}
\hline & $\begin{array}{l}\text { Alcon AcrySof }{ }^{\circ} \\
\text { MA60AC }\end{array}$ & $\begin{array}{l}\text { HOYA iSert@ PC- } \\
60 \mathrm{AD}\end{array}$ & $\begin{array}{l}\text { Bausch\&Lomb } \\
\text { enVista }\end{array}$ & $\begin{array}{l}\text { KOWA Avansee } \\
\text { AU6KA }\end{array}$ \\
\hline $\begin{array}{l}\text { Alcon AcrySof } \AA \\
\text { MA60AC }\end{array}$ & & $0.032 *$ & $0.009 *$ & $0.009^{*}$ \\
\hline Hoya iSert ${ }^{\circledR}$ PC-60AD & $0.032 *$ & & $0.009 *$ & $0.009^{*}$ \\
\hline Bausch\&Lomb enVista & $0.009 *$ & $0.009 *$ & & 0.914 \\
\hline $\begin{array}{l}\text { Kowa Avansee }^{\mathrm{TM}} \\
\text { AU6KA }\end{array}$ & $0.009^{*}$ & $0.009 *$ & 0.914 & \\
\hline
\end{tabular}

* Statistically significant difference $(p<0.05$, Mann-Whitney $U$ test) 
Table 4 Distribution of the microvacuole size in all studied lenses

\begin{tabular}{|c|c|c|c|c|c|c|c|}
\hline \multicolumn{8}{|c|}{ Mean microvacuole size $\left(\mathrm{MV} / \mathrm{mm}^{2}\right)$ and distribution } \\
\hline & $\begin{array}{l}\text { Class } 1 \\
0-5 \mu \mathrm{m}\end{array}$ & $\begin{array}{l}\text { Class } 2 \\
5-10 \mu \mathrm{m}\end{array}$ & $\begin{array}{l}\text { Class } 3 \\
10-15 \mu \mathrm{m}\end{array}$ & $\begin{array}{l}\text { Class } 4 \\
15-20 \mu \mathrm{m}\end{array}$ & $\begin{array}{l}\text { Class } 5 \\
20-50 \mu \mathrm{m}\end{array}$ & $\begin{array}{l}\text { Class } 6 \\
50-100 \mu \mathrm{m}\end{array}$ & $\begin{array}{l}\text { No } \\
\text { Class }>100 \mu \mathrm{m}\end{array}$ \\
\hline $\begin{array}{l}\text { Hoya iSert }{ }^{\circledR} \text { PC- } \\
\text { 60AD }\end{array}$ & 1785 & 831.4 & 141 & 35.2 & 15.6 & 0.6 & 0 \\
\hline $\begin{array}{l}\text { Alcon AcrySof }{ }^{\circledR} \\
\text { MA60AC }\end{array}$ & 412.8 & 604.8 & 74.4 & 11.8 & 0.8 & 0 & 0 \\
\hline $\begin{array}{l}\text { Bausch\&Lomb } \\
\text { enVista }\end{array}$ & 0 & 0.4 & 0.8 & 1 & 1.8 & 0.2 & 0 \\
\hline $\begin{array}{l}\text { Kowa Avansee } \\
\text { AU6KA }\end{array}$ & 0 & 1 & 0.6 & 0.6 & 0.8 & 0.2 & 0 \\
\hline
\end{tabular}

new Clareon material introduced by Alcon, which was shown to be glistening-free in preclinical in vitro studies [32]. However, the material evaluatedhere is also still used, even in more modern IOL optics $[33,34]$. Hoya has also already introduced a new glistening-free material called Vivinex [35, 36].

Our results permit a comparison between different IOL models in their tendency to produce glistenings, and we demonstrated that this tendency can be significantly lowered in IOLs composed of modern IOL materials.

Authors' contribution All authors contributed to the study conception and design. Material preparation, data collection, and analysis were performed by TT, CYC, HSS, and RK. The first draft of the manuscript was written by TT, CYC, HSS, and RK, and GUA and RK read, revised, and approved the final manuscript.

Funding Open Access funding enabled and organized by Projekt DEAL. The David J. Apple Laboratory received funding from the Klaus Tschira Foundation, Heidelberg, Germany. The funding organization had no role in the design or conduct of this research.

Data availability The datasets used and/or analysed during the current study are available from the corresponding author on reasonable request.

\section{Declarations}

Conflict of interest GUA and RK received research grants from Alcon, Kowa, Carl Zeiss Meditec, Hoya, Bausch\&Lomb, Ophthec, Physiol, Powervision, Rayner, SIFI, Johnson\&Johnson, Acufocus, and Oculentis. TT and CYC received research grants from Hoya, Alcon, Bausch\&Lomb, and Kowa. HSS has no competing interests to disclose.
Open Access This article is licensed under a Creative Commons Attribution 4.0 International License, which permits use, sharing, adaptation, distribution and reproduction in any medium or format, as long as you give appropriate credit to the original author(s) and the source, provide a link to the Creative Commons licence, and indicate if changes were made. The images or other third party material in this article are included in the article's Creative Commons licence, unless indicated otherwise in a credit line to the material. If material is not included in the article's Creative Commons licence and your intended use is not permitted by statutory regulation or exceeds the permitted use, you will need to obtain permission directly from the copyright holder. To view a copy of this licence, visit http://creativecommons.org/licenses/by/4.0/.

\section{References}

1. Khoramnia R, Yildirim TM, Łabuz G, Mayer CS, Auffarth GU (2020) Eintrübung von intraokularlinsen: erkenntnisse aus demlabor und der Klinik [Opacification of intraocular lenses: laboratory and clinical findings]. Ophthalmologe. Nov 13. German. https://doi.org/10.1007/s00347-02001259-3

2. Kanclerz P, Yildirim TM, Khoramnia R (2021) A review of late intraocular lens opacifications. Curr Opin Ophthalmol 32(1):31-44

3. Kanclerz P, Yildirim TM, Khoramnia R (2020) Microscopic characteristics of late intraocular lens opacifications. Arch PatholLab Med. https://doi.org/10.5858/arpa.2019-0626RA

4. Ramin, Khoramnia [Opacification of Intraocular Lenses]. Klinische Monatsblätter für Augenheilkunde. https://doi. org/10.1055/a-1472-0570

5. Weindler JN, Łabuz G, Yildirim TM, Tandogan T, Khoramnia R, Auffarth GU (2019) The impact of glistenings on the optical quality of a hydrophobic acrylic intraocular lens. J Cataract Refract Surg 45(7):1020-1025

6. Beiko GH, Grzybowski A (2013) Glistenings in hydrophobic acrylic intraocular lenses do affect visual function. Clin Ophthalmol 7:2271-2274 
7. Rønbeck M, Behndig A, Taube M, Koivula A, Kugelberg M (2013) Comparison of glistenings in intraocular lenses with three different materials: 12-year follow-up. Acta Ophthalmol 91(1):66-70

8. Christiansen G, Durcan FJ, Olson RJ, Christiansen K (2001) Glistenings in the AcrySof intraocular lens: pilot study. J Cataract Refract Surg 27(5):728-733

9. Gunenc U, Gunenc U, Oner FH, Tongal S, Ferliel M (2001) Effects on visual function of glistenings and folding marks in AcrySof intraocular lenses. J Cataract Refract Surg 27(10):1611-1614

10. Matsushima H, Nagata M, Katsuki Y, Ota I, Miyake K, Beiko GH, Grzybowski A (2015) Decreased visual acuity resulting from glistening and sub-surface nano-glistening formation in intraocular lenses: a retrospective analysis of 5 cases. Saudi J Ophthalmol 29(4):259-263

11. Leaming DV (2004) Practice styles and preferences of ASCRS members-2003 survey. J Cataract Refract Surg 30(4):892-900

12. Werner L (2010) Glistenings and surface light scattering in intraocular lenses. J Cataract Refract Surg 36(8):1398-1420

13. Tognetto D, Toto L, Sanguinetti G, Ravalico G (2002) Glistenings in foldable intraocular lenses. J Cataract Refract Surg 28(7):1211-1216

14. Thomes BE, Callaghan TA (2013) Evaluation of in vitro glistening formation in hydrophobic acrylic intraocular lenses. Clin Ophthalmol 7:1529-1534

15. Miyata A, Uchida N, Nakajima K, Yaguchi S (2000) Clinical and experimental observation of glistening in acrylic intraocular lenses. Jpn J Ophthalmol 44(6):693

16. Kato K, Nishida M, Yamane H, Nakamae K, Tagami Y, Tetsumoto K (2001) Glistening formation in an AcrySof lens initiated by spinodal decomposition of the polymer network by temperature change. J Cataract Refract Surg 27(9):1493-1498

17. Gregori NZ, Spencer TS, Mamalis N, Olson RJ (2002) In vitro comparison of glistening formation among hydrophobic acrylic intraocular lenses(1). J Cataract Refract Surg 28(7):1262-1268

18. Kawak K, Hayakawa K, Suzuki T (2012) Simulation of 20 -year deterioration of acrylic IOLs using severe accelerated deterioration tests. Tokai J Exp Clin Med 37(3):62-65

19. Miyata A, Yaguchi S (2004) Equilibrium water content and glistenings in acrylic intraocular lenses. J Cataract Refract Surg 30(8): 1768-1772

20. Omar O, Pirayesh A, Mamalis N, Olson RJ (1998) In vitro analysis of AcrySof intraocular lens glistenings in AcryPak and Wagon Wheel packaging. J Cataract Refract Surg 24(1):107-113

21. Packer M, Rajan M, Ligabue E, Heiner P (2014) Clinical properties of a novel, glistening-free, single-piece, hydrophobic acrylic IOL. Clin Ophthalmol 21(8):421-427

22. Dogru M, Tetsumoto K, Tagami Y, Kato K, Nakamae K (2000) Optical and atomic force microscopy of an explanted AcrySof intraocular lens with glistenings. J Cataract Refract Surg 26(4):571-575

23. Dhaliwal DK, Mamalis N, Olson RJ, Crandall AS, Zimmerman P, Alldredge OC, Durcan FJ, Omar O (1996) Visual significance of glistenings seen in the AcrySof intraocular lens. J Cataract Refract Surg 22(4):452-457
24. Xi L, Liu Y, Zhao F, Chen C, Cheng B (2014) Analysis of glistenings in hydrophobic acrylic intraocular lenses on visual performance. Int J Ophthalmol 7(3):446-451

25. Packer M, Fry L, Lavery KT, Lehmann R, McDonald J, Nichamin L, Bearie B, Hayashida J, Altmann GE, Khodai O (2013) Safety and effectiveness of a glistening-free singlepiece hydrophobic acrylic intraocular lens (enVista). Clin Ophthalmol 7:1905-1912

26. Heiner P, Ligabue E, Fan A, Lam D (2014) Safety and effectiveness of a single-piece hydrophobic acrylic intraocular lens (enVista $\left.{ }^{\circledR}\right)$ - results of a European and Asian-Pacific study. Clin Ophthalmol 27(8):629-635

27. Mönestam E, Behndig A (2011) Impact on visual function from light scattering and glistenings in intraocular lenses, a long-term study. Acta Ophthalmol 89(8):724-728

28. Wilkins E, Olson RJ (2001) Glistenings with long-term follow-up of the Surgidev B20/20 polymethylmethacrylate intraocular lens. Am J Ophthalmol 132(5):783-785

29. Colin J, Orignac I (2011) Glistenings on intraocular lenses in healthy eyes: effects and associations. J Refract Surg 27(12):869-875

30. Waite A, Faulkner N, Olson RJ (2007) Glistenings in the single-piece, hydrophobic, acrylic intraocular lenses. Am J Ophthalmol 144(1):143-144

31. Łabuz G, Knebel D, Auffarth GU, Fang H, van den Berg TJ, Yildirim TM, Son HS, Khoramnia R (2018) Glistening formation and light scattering in six hydrophobic-Acrylic intraocular lenses. Am J Ophthalmol 196:112-120

32. Wang Q, Yildirim TM, Schickhardt SK, Łabuz G, Khoramnia R, Merz PR, Son HS, Munro DJ, Friedmann E, Auffarth GU (2021) Quantification of the in vitro predisposition to glistening formation in one manufacturer's acrylic intraocular lenses made in different decades. Ophthalmol Ther 10(1):165-174

33. Isabella, Baur Gerd U., Auffarth Grzegorz, Łabuz Ramin, Khoramnia (2021) Unilateral implantation of a new nondiffractiveextended range-of-vision IOL in a young patient with Curschmann-Steinert myotonic dystrophy. Am J Ophthalmol Case Rep 22101109. https://doi.org/10.1016/j. ajoc.2021.101109

34. Baur ID, Auffarth GU, Łabuz G, Mayer CS, Khoramnia R. Ophthalmologe. 2020 Dec 10. [Unilateral implantation of a new extended range of vision intraocular lens in a young patient] (in press). https://doi.org/10.1007/s00347-02001285-1

35. Tandogan T, Auffarth GU, Son HS, Merz P, Choi CY, Khoramnia R (2021) In-vitro glistening formation in six different foldable hydrophobic intraocular lenses. BMC Ophthalmol 21(1):126

36. Yildirim TM, Schickhardt SK, Qiang W, Friedmann E, Khoramnia R, Auffarth GU (2021) Quantitative evaluation of microvacuole formation in five intraocular lens models made of differenthydrophobic materials. PLOS ONE 16(4):e0250860. https://doi.org/10.1371/journal.pone. 0250860

Publisher's Note Springer Nature remains neutral with regard to jurisdictional claims in published maps and institutional affiliations. 